\title{
High Signal Intensity in the Dentate Nucleus and Globus Pallidus on Unenhanced T1-Weighted MR Images: Comparison between Gadobutrol and Linear Gadolinium-Based Contrast Agents
}

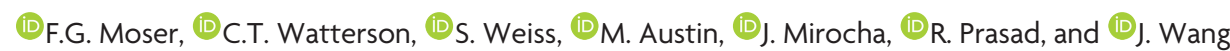

\begin{abstract}
BACKGROUND AND PURPOSE: In view of the recent observations that gadolinium deposits in brain tissue after intravenous injection, our aim of this study was to compare signal changes in the globus pallidus and dentate nucleus on unenhanced T1-weighted MR images in patients receiving serial doses of gadobutrol, a macrocyclic gadolinium-based contrast agent, with those seen in patients receiving linear gadolinium-based contrast agents.
\end{abstract}

MATERIALS AND METHODS: This was a retrospective analysis of on-site patients with brain tumors. Fifty-nine patients received only gadobutrol, and 60 patients received only linear gadolinium-based contrast agents. Linear gadolinium-based contrast agents included gadoversetamide, gadobenate dimeglumine, and gadodiamide. $\mathrm{Tl}$ signal intensity in the globus pallidus, dentate nucleus, and pons was measured on the precontrast portions of patients' first and seventh brain MRIs. Ratios of signal intensity comparing the globus pallidus with the pons (globus pallidus/pons) and dentate nucleus with the pons (dentate nucleus/pons) were calculated. Changes in the above signal intensity ratios were compared within the gadobutrol and linear agent groups, as well as between groups.

RESULTS: The dentate nucleus/pons signal ratio increased in the linear gadolinium-based contrast agent group $(t=4.215, P<.001)$, while no significant increase was seen in the gadobutrol group $(t=-1.422, P=.08)$. The globus pallidus/pons ratios followed similarly, with an increase in the linear gadolinium-based contrast agent group $(t=2.931, P<.0001)$ and no significant change in those receiving gadobutrol $(t=0.684, P=.25)$.

CONCLUSIONS: Successive doses of gadobutrol do not result in $\mathrm{T} 1$ shortening compared with changes seen in linear gadolinium-based contrast agents.

ABBREVIATIONS: $\mathrm{DN}=$ dentate nucleus; $\mathrm{GBCA}=$ gadolinium-based contrast agent; $\mathrm{GP}=$ globus pallidus

$\mathbf{T}$ he use of gadolinium-based contrast agents (GBCAs) has become an important adjunct for MR imaging examinations. Although GBCAs are considered extremely safe in patients without renal failure, it is known that free gadolinium $\left(\mathrm{Gd}^{3+}\right)$ is toxic to humans. The ability of a chelating agent to retain the gadolinium and therefore maintain its safety profile has been shown to correlate with the structure and stability of the chelating molecule. ${ }^{1}$ As demonstrated by both in vivo and in vitro studies, macrocyclic chelating

Received June 26, 2017; accepted after revision November 15.

From the Department of Imaging (F.G.M., C.T.W., S.W., R.P.), S. Mark Taper Foundation Imaging Center, and Samuel Oschin Comprehensive Cancer Institute (J.M.), Cedars Sinai Medical Center, Los Angeles, California; Department of Radiology (M.A.), Lahey Clinic, Burlington, Massachusetts; and Bayer Healthcare (J.W.), Whippany, New Jersey.

This work was supported by Bayer Healthcare, Project No. 00042369.

Please address correspondence to Franklin G. Moser, MD, MMM, Department of Imaging, S. Mark Taper Foundation Imaging Center, Cedars Sinai Medical Center, 8700 Beverly Blvd, Los Angeles, CA 90048; e-mail: Franklin.Moser@cshs.org; @fgmosermd

http://dx.doi.org/10.3174/ajnr.A5538 agents are generally more stable than linear ones, bind $\mathrm{Gd}^{3+}$ more tightly, and have lower dissociation rates. ${ }^{1-5}$

Recent data indicate that patients exposed to multiple administrations of certain GBCAs may exhibit dose-related T1 shortening in the globus pallidus (GP) and dentate nucleus (DN). ${ }^{6-12}$ Moreover, these imaging findings have correlated with gadolinium deposition in the GP and DN on postmortem examinations, even in patients with relatively normal renal function. ${ }^{13,14}$ Increased signal intensity in the GP and DN on unenhanced T1weighted MR images has been positively correlated with prior exposure to both ionic and nonionic linear GBCAs in patients. ${ }^{6}$

Results regarding macrocyclic agents have been more varied. In 2015, Kanda et $\mathrm{al}^{10}$ found that hyperintensity in the DN was associated with past administration of the linear GBCA gadopentetate dimeglumine (Magnevist; Bayer HealthCare Pharmaceuticals, Wayne, New Jersey) but not with the macrocyclic GBCA gadoteridol (ProHance; Bracco Diagnostics, Princeton, New Jersey). While Radbruch et $\mathrm{al}^{9}$ did not find a significant signal inten- 
sity increase in the DN and GP after progressive applications of the macrocyclic GBCA gadoterate meglumine (Dotarem; Guerbet, Aulnay-sous-Bois, France), Stojanov et al ${ }^{12}$ found a significant increase in signal intensity within the DN and GP in patients with relapsing-remitting multiple sclerosis after multiple doses of the macrocyclic GBCA gadobutrol (Gadavist; Bayer Schering Pharma, Berlin, Germany). The study of Stojanov et al suggests that deposition of gadolinium within the brain may occur not solely as the result of linear GBCA administration but also with some types of macrocyclic agents. To confuse matters, the reports of Stojanov et al were quickly disputed by multiple contradicting studies showing no T1 signal change following the administration of the widely used macrocyclic agent gadobutrol. ${ }^{15,16}$

Additionally, direct comparison between linear and macrocyclic GBCAs still must be explored. For example, while Stojanov et $\mathrm{al}^{12}$ have demonstrated T1 shortening in the GP and DN following repeat administration of gadobutrol, the relative degree of these changes compared with those seen in linear-based agents has not been determined, and the results have been since challenged by a number of follow-up studies. ${ }^{16-18}$ The purpose of this study was to compare possible gadobutrol-related T1 signal intensity changes with those of linear agents in a similar population. Prior studies evaluating such T1 changes following the use of gadobutrol have resulted in limited power or cumulative dose per patient. $^{15,16}$

\section{MATERIALS AND METHODS}

Whole-brain MR imaging was performed using 1.5T (Symphony; Siemens, Erlangen, Germany) or 3T (Verio; Siemens) MR imaging units. Unenhanced T1-weighted MR images (3D MPRAGE) were obtained with the following parameters on $1.5 \mathrm{~T}$ systems: $\mathrm{TR}=1330 \mathrm{~ms} ; \mathrm{TE}=4.8 \mathrm{~ms} ; \mathrm{TI}=800 \mathrm{~ms}$; flip angle $=15^{\circ}$; section thickness $=12.5 \mathrm{~mm}$; matrix size $=256 \times 192$; echo-train length $=1$. T1-weighting parameters on $3 \mathrm{~T}$ systems were the following: $\mathrm{TR}=2100 \mathrm{~ms} ; \mathrm{TE}=3.0 \mathrm{~ms} ; \mathrm{TI}=900 \mathrm{~ms}$; flip angle $=$ $9^{\circ}$; section thickness $=11 \mathrm{~mm}$; matrix size $=256 \times 256$; echotrain length $=1$.

Following institutional review board approval, patients were retrospectively selected from among neuroimaging patients at Cedars-Sinai Medical Center. Informed consent was waived given the retrospective nature of the study. The population selected for study consisted of patients who had undergone at least 7 prior contrast-enhanced MR imaging examinations. Due to the relative frequency of contrast-enhanced examinations associated with standard care, all patients had intra-axial malignancy, most commonly anaplastic astrocytoma or glioblastoma multiforme. All patients receiving gadolinium contrast agents had been screened for renal failure with serum creatinine levels.

As a result of an institution-wide contrast formulary policy change, it was simple to determine which contrast agents patients received. Before 2011, our institution had exclusively used linear, nonionic contrast agents, gadoversetamide (OptiMARK; Covidien, Irvine, California) and, to a lesser extent, gadodiamide (Omniscan; GE Healthcare, Piscataway, New Jersey). Between 2011 and February 2012, gadobenate dimeglumine (MultiHance; Bracco Diagnostics), a linear, ionic GBCA, became the primary

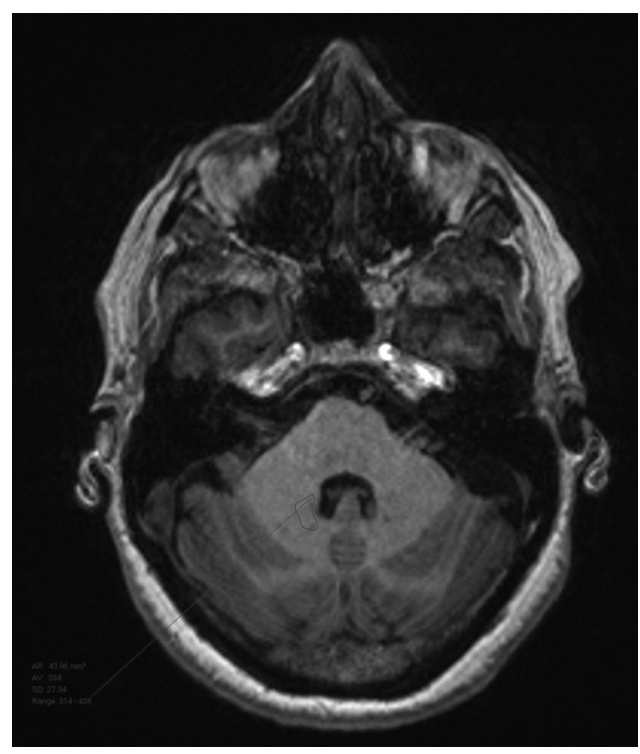

FIG 1. Dentate nucleus ROI selection.

contrast agent. After February 2012, we began to exclusively use gadobutrol (Gadavist), a macrocyclic GBCA, for all neuroimaging. This allowed us to have a population of patients who had received only the macrocyclic agent gadobutrol to compare against an earlier population who had received only linear GBCAs.

We used the following inclusion criteria: 1) Patients must have undergone at least 7 consecutive studies with gadobutrol or at least 7 scans with only linear contrast agents (OptiMARK, MultiHance, and Omniscan); 2) initial and final MRIs had both preand postcontrast T1-weighted images; 3) one class of contrast agent was exclusively used for all 7 examinations, either macrocyclic (exclusively gadobutrol) or linear (any combination of those mentioned above); 4) at least 1 basal ganglion and the posterior fossa were spared tumor or radiation effects; 5) subjects had normal renal function, defined as a glomerular filtration rate of $>30$; and 6) the seventh examination occurred at least 2 weeks following the sixth. Patients were excluded on the basis of the following: 1) tumor- or treatment-related change in the posterior fossa or bilateral globi pallidi; and 2) abnormal baseline T1 signal intensity ratio of $>1$ :1 when comparing the $\mathrm{DN}$ with the pons.

The study population was divided into 2 groups: Group 1 included patients who received only gadobutrol, and group 2 included patients who received only linear contrast agents (OptiMARK, MultiHance, Omniscan). Following exclusion, group 1 contained 59 patients while group 2 contained 60. Anonymized data for each group were collected using Excel (Microsoft, Redmond, Washington) and were stored on-site in an encrypted fashion.

Two radiologists conducted a quantitative analysis of unenhanced T1-weighted images using ROI measurements. Measurements were made on the baseline scan and the seventh scan. In keeping with previously described techniques, ROIs were drawn over the left globus pallidus, dentate nucleus, lateral ventricle, and pons, and average signal intensity was recorded. ${ }^{12,19}$ Examples of ROI selection are presented as Figs 1-3. We compared DN and GP signal intensities with T1 measurements of the pons and calcu- 


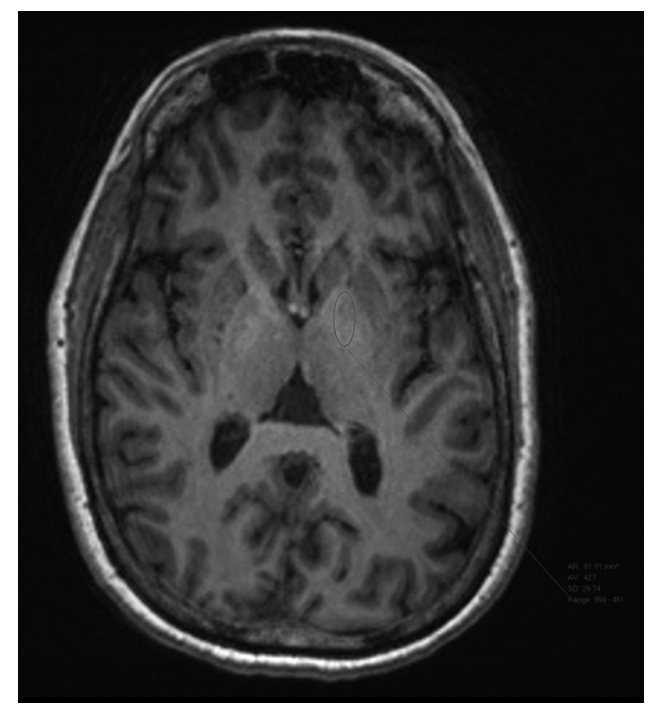

FIG 2. Globus pallidus ROI selection.

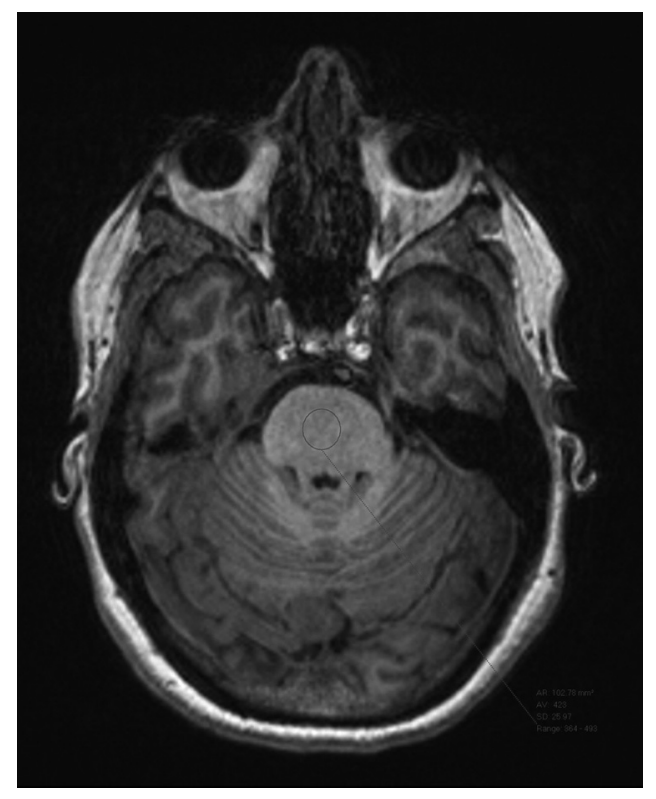

FIG 3. Pons ROI selection.

lated the ratios of these intensities: dentate nucleus/pons (DN/ pons) and globus pallidus/pons (GP/pons). ${ }^{12}$ If the left side could not be evaluated due to artifacts or pathology, the right side was used.

\section{Statistical Analysis}

In keeping with other authors' methods, it was decided that it would be best to compare ratios between the GP and pons as well as the DN and pons. Paired $t$ tests were used to compare changes within a given group (ie, the gadobutrol group or the linear agent group) between the first and seventh examinations. Wilcoxon rank sum tests were used for between-group comparisons of the percentage change in the signal intensity ratio (either DN/pons or GP/pons) seen during the patients' 7 examinations. All statistical analysis was performed with Statistical Analysis Software, Version 9.2 (SAS Institute, Cary, North Carolina).
Table 1: Paired $t$ test comparing DN/pons and GP/pons at time 1 versus 7 within groups

\begin{tabular}{|c|c|c|c|c|}
\hline & \multicolumn{2}{|c|}{ DN/Pons } & \multicolumn{2}{|c|}{ GP/Pons } \\
\hline & $\begin{array}{c}\text { Group 1: } \\
\text { Gadobutrol }\end{array}$ & $\begin{array}{c}\text { Group 2: } \\
\text { Linear } \\
\text { Agents }\end{array}$ & $\begin{array}{c}\text { Group 1: } \\
\text { Gadobutrol }\end{array}$ & $\begin{array}{c}\text { Group 2: } \\
\text { Linear } \\
\text { Agents }\end{array}$ \\
\hline No. & 59 & 60 & 59 & 60 \\
\hline Mean change & -0.01 & 0.03 & -0.01 & 0.03 \\
\hline SD & $<0.005$ & $<0.005$ & $<0.005$ & 0.01 \\
\hline$t$ & -1.422 & 4.215 & -0.684 & 2.931 \\
\hline$P$ & .08 & $<.001$ & .25 & .002 \\
\hline
\end{tabular}
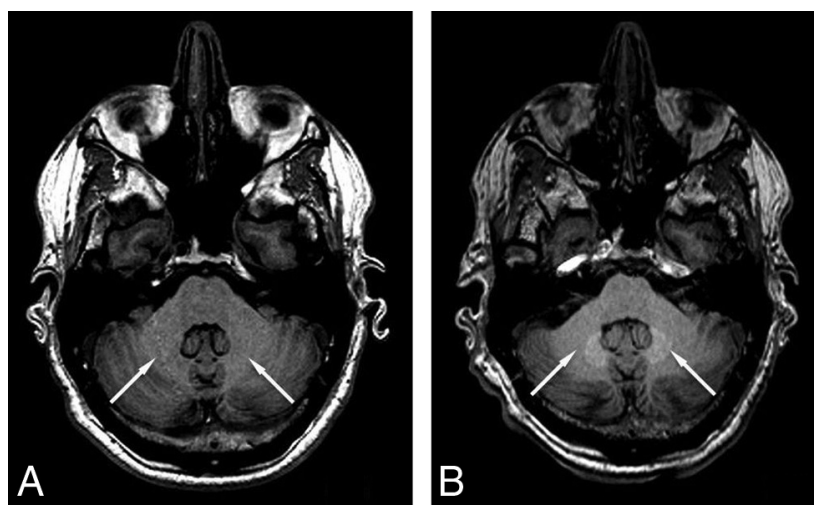

FIG 4. Sample images showing obvious signal increase, indicated by arrows, after 6 injections of linear GBCAs $(B)$ compared with the baseline scan $(A)$.

\section{RESULTS}

Consistent with expectations, a significant signal intensity increase was detected in the DN/pons ratio by the seventh examination in the linear agent group $(t=4.215, P<.001$; Table 1$)$. A sample pair of images showing the signal increase is shown in Fig 4. No significant change was demonstrated in the group receiving gadobutrol $(t=-1.422, P=.08$; Table 1$)$. The difference between the signal changes seen in these 2 groups was also significant $(+3.10 \%$ for those receiving linear GBCA; $-0.8 \%$ for patients receiving gadobutrol; $P<.0001$; Fig 5 and Table 2).

Similarly, a significant increase was seen in the GP/pons ratio in the linear agent group between the first and seventh examinations $(t=2.931, P=.002$; Table 1$)$, while no such increase was seen in the group receiving gadobutrol $(t=0.684, P=.25$; Table $1)$. Again, the difference in the percentage change between these groups was significant $(+2.47 \%$ for the linear GBCA group; $-0.30 \%$ in the gadobutrol group, $P=.033$; Fig 6 and Table 2).

\section{DISCUSSION}

The demonstration of a stable $\mathrm{DN} /$ pons $\mathrm{T} 1$ signal intensity ratio over subsequent administrations of gadobutrol supports the growing preponderance of evidence suggesting that macrocyclic GBCAs, as a class, are less likely to deposit gadolinium in the brain. As with previous examinations, the use of linear GBCAs was found to result in increased T1 signal in the globus pallidus and dentate nucleus.

There are several limitations to our study. Patient age was not controlled for, in favor of improving sample size. While all patients were seen for malignancy, nearly all with anaplastic astrocytoma or glioblastoma multiforme, the distributions of these 
Table 2: Wilcoxon test comparing percentage change in DN/pons and GP/pons ratios from study 1 to study 7 between the gadobutrol and linear groups

\begin{tabular}{lcccrcc}
\hline \multicolumn{1}{c}{ Group } & No. & Percentage Change (Mean) & SD & Median & Lower Quartile & Upper Quartile \\
\hline DN/Pons & & & & & & \\
Gadobutrol (group 1) & 59 & -0.80 & 4.78 & -0.66 & -4.24 & 2.21 \\
Linear GBCAs (group 2) & 60 & 3.10 & 5.56 & 3.70 & -0.52 & 6.76 \\
GP/Pons & & -0.30 & 5.44 & 0.72 & -3.56 & \\
$\quad$ Gadobutrol (group 1) & 59 & 2.47 & 6.53 & 2.05 & -2.56 & 6.48 \\
Linear GBCAs (group 2) & 60 & & & &
\end{tabular}

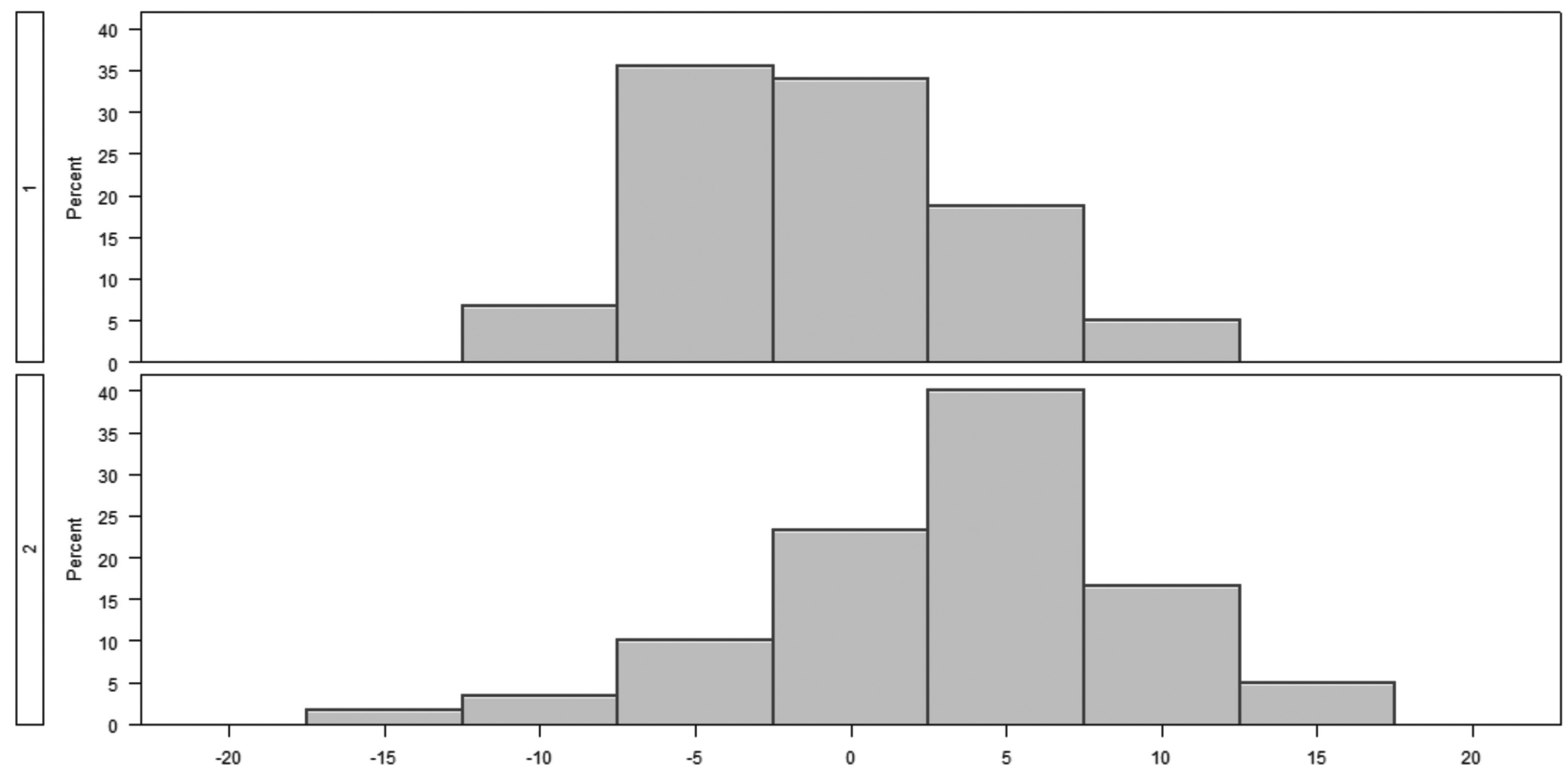

FIG 5. Group histograms for the relative percentage change in the DN/pons ratio from 1 to 7 .

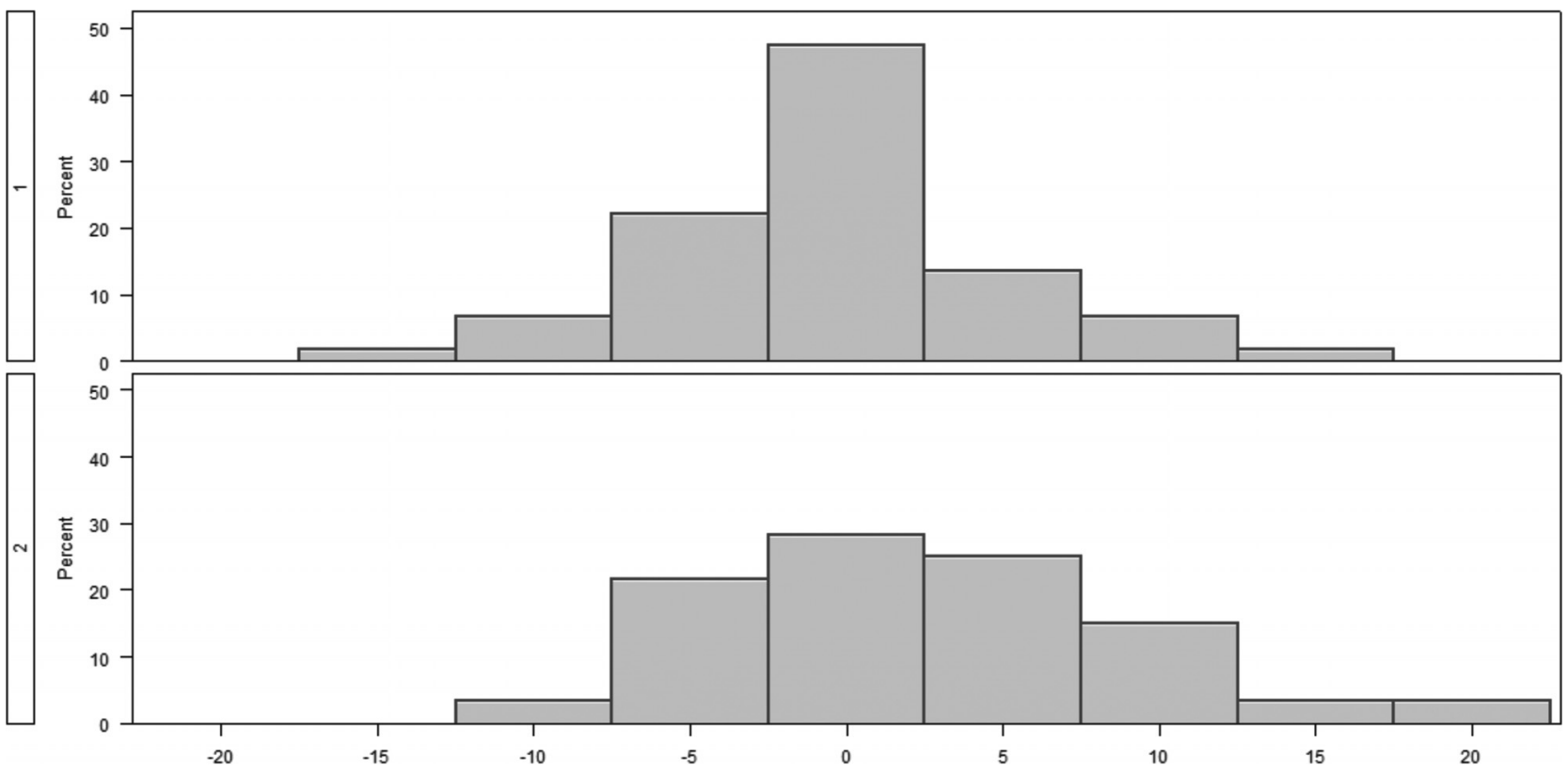

FIG 6. Group histograms for the relative percentage change in the GP/pons ratio from 1 to 7 .

malignancies and relative chemotherapy effects were not controlled for. The damage to the BBB caused by disease processes, treatment, or both is also a potential confounding variable because most patients undergoing repeat brain MRIs have a known intracranial malignancy. Both $1.5 \mathrm{~T}$ and $3 \mathrm{~T}$ systems were used. While most examinations were performed at $1.5 \mathrm{~T}$, differences in equipment may have resulted in slight variations on measurements. There was also no intra-/interobserver agreement separately 
before this study because the average signal intensity measurement is normally less sensitive to intra-/interobserver variations.

Our study has only explored the contribution of gadobutrol to signal intensity change in up to 7 injections, so the possibility of observing a signal intensity increase cannot be excluded in patients with even higher cumulative gadobutrol injection doses. Even though we tried to ensure the completeness of all participants' medical records, the possibility of any unknown prior GBCA usage cannot be excluded for all patients.

Although most studies in the literature on the gadolinium deposition topic are MR imaging-based, inductively coupled plasma mass spectrometry-based postmortem tissue sampling studies, which have much higher sensitivity to the existence of gadolinium atoms, have also been conducted in both preclinical and clinical studies. Because of the higher sensitivity of inductively coupled plasma mass spectrometry techniques, deposits from both linear and macrocyclic agents have been reported, ${ }^{20-23}$ though the amount of deposition from macrocyclic agents was found to be much lower than from linear counterparts. Presumably, they are not as easily detected by standard T1-weighted MR imaging because of the lower deposition rate of macrocyclic agents.

Most interesting, while not statistically significant, patients receiving gadobutrol showed an unexpected decrease in signal intensity in both the DN and GP between the first and seventh studies. The decrease in the $\mathrm{DN} /$ pons ratio was found to be nearly significant at $P=.08$. Because linear GBCA administration before 2012 was not controlled for in the gadobutrol group, it is possible that this decrease reflects the results of clearance of previously deposited gadolinium from prior administrations, which may corroborate developing research on clearance and the efficacy of a "gadolinium holiday." 24 Alternatively, this nonsignificant signal decrease could also be caused by the bias in patient sampling and in signal measurement inherent in ROI-based analysis.

\section{CONCLUSIONS}

Patients exposed to gadobutrol, a macrocyclic agent, failed to show a demonstrable change in $\mathrm{T} 1$ signal intensity in the regions of the brain classically susceptible to gadolinium deposition. This finding corroborates evidence suggesting that macrocyclic agents are less likely to cause signal increase on nonenhanced T1WI MR images than linear GBCAs.

Disclosures: Franklin G. Moser-RELATED: Grant: Bayer Healthcare, Comments: grant to conduct research.* Christopher T. Watterson—RELATED: Grant: Bayer Healthcare, Comments: educational grant.* Sasha Weiss—RELATED: Grant: Bayer Healthcare.* James Mirocha—RELATED: Grant: Bayer Healthcare.* Jinnan Wang—UNRELATED: Employment: Bayer Healthcare; Stock/Stock Options: Bayer Healthcare. *Money paid to the institution.

\section{REFERENCES}

1. Frenzel T, Lengsfeld P, Schirmer H, et al. Stability of gadoliniumbased magnetic resonance imaging contrast agents in human serum at 37 degrees C. Invest Radiol 2008;43:817-28 CrossRef Medline

2. Morcos SK. Extracellular gadolinium contrast agents: differences in stability. Eur J Radiol 2008;66:175-79 CrossRef Medline

3. Kanal E, Maravilla K, Rowley HA. Gadolinium contrast agents for CNS imaging: current concepts and clinical evidence. AJNR Am J Neuroradiol 2014;35:2215-26 CrossRef Medline

4. Maravilla KR, Smith MP, Vymazal J, et al. Are there differences between macrocyclic gadolinium contrast agents for brain tumor im- aging? Results of a multicenter intraindividual crossover comparison of gadobutrol with gadoteridol (the TRUTH study). AJNR AmJ Neuroradiol 2015;36:14-23 CrossRef Medline

5. Lin SP, Brown JJ. MR contrast agents: physical and pharmacologic basics. J Magn Reson Imaging 2007;25:884-99 CrossRef Medline

6. Kanda T, Ishii K, Kawaguchi $\mathrm{H}$, et al. High signal intensity in the dentate nucleus and globus pallidus on unenhanced T1-weighted MR images: relationship with increasing cumulative dose of a gadolinium-based contrast material. Radiology 2014;270:834-41 CrossRef Medline

7. Errante Y, Cirimele V, Mallio CA, et al. Progressive increase of T1 signal intensity of the dentate nucleus on unenhanced magnetic resonance images is associated with cumulative doses of intravenously administered gadodiamide in patients with normal renal function, suggesting dechelation. Invest Radiol 2014;49:685-90 CrossRef Medline

8. Quattrocchi CC, Mallio CA, Errante Y, et al. Gadodiamide and dentate nucleus $\mathrm{T} 1 \mathrm{hyperintensity}$ in patients with meningioma evaluated by multiple follow-up contrast-enhanced magnetic resonance examinations with no systemic interval therapy. Invest Radiol 2015; 50:470-72 CrossRef Medline

9. Radbruch A, Weberling LD, Kieslich PJ, et al. Gadolinium retention in the dentate nucleus and globus pallidus is dependent on the class of contrast agent. Radiology 2015;275:783-91 CrossRef Medline

10. Kanda T, Osawa M, Oba $\mathrm{H}$, et al. High signal intensity in dentate nucleus on unenhanced T1-weighted MR images: association with linear versus macrocyclic gadolinium chelate administration. $R a$ diology 2015;275:803-09 CrossRef Medline

11. Ramalho J, Castillo M, AlObaidy M, et al. High signal intensity in globus pallidus and dentate nucleus on unenhanced T1-weighted MR images: evaluation of two linear gadolinium-based contrast agents. Radiology 2015;276:836-44 CrossRef Medline

12. Stojanov DA, Aracki-Trenkic A, Vojinovic S, et al. Increasing signal intensity within the dentate nucleus and globus pallidus on unenhanced T1W magnetic resonance images in patients with relapsingremitting multiple sclerosis: correlation with cumulative dose of a macrocyclic gadolinium-based contrast agent, gadobutrol. Eur Radiol 2016;26:807-15 CrossRef Medline

13. McDonald RJ, McDonald JS, Kallmes DF, et al. Intracranial gadolinium deposition after contrast-enhanced MR imaging. Radiology 2015;275:772-82 CrossRef Medline

14. Kanda T, Fukusato T, Matsuda M, et al. Gadolinium-based contrast agent accumulates in the brain even in subjects without severe renal dysfunction: evaluation of autopsy brain specimens with inductively coupled plasma mass spectroscopy. Radiology 2015;276: 228-32 CrossRef Medline

15. Kromrey ML, Liedtke KR, Ittermann $\mathrm{T}$, et al. Intravenous injection of gadobutrol in an epidemiological study group did not lead to a difference in relative signal intensities of certain brain structures after 5 years. Eur Radiol 2017;27:772-77 CrossRef Medline

16. Radbruch A, Weberling LD, Kieslich PJ, et al. High-signal intensity in the dentate nucleus and globus pallidus on unenhanced T1weighted images: evaluation of the macrocyclic gadolinium-based contrast agent gadobutrol. Invest Radiol 2015;50:805-10 CrossRef Medline

17. Cao Y, Huang DQ, Shih G, et al. Signal change in the dentate nucleus on T1-weighted MR images after multiple administrations of gadopentetate dimeglumine versus gadobutrol. AJR Am J Roentgenol 2016;206:414-19 CrossRef Medline

18. Schlemm L, Chien C, Bellmann-Strobl J, et al. Gadopentetate but not gadobutrol accumulates in the dentate nucleus of multiple sclerosis patients. Mult Scler 2017;23:963-72 CrossRef Medline

19. Moser FG, Hilal SK, Abrams G, et al. MR imaging of pseudotumor cerebri. AJR Am J Roentgenol 1988;150:903-09 CrossRef Medline

20. Robert P, Violas X, Grand S, et al. Linear gadolinium-based contrast agents are associated with brain gadolinium retention in healthy rats. Invest Radiol 2016;51:73-82 CrossRef Medline

21. Lohrke J, Frisk AL, Frenzel T, et al. Histology and gadolinium distribution in the rodent brain after the administration of cumulative 
high doses of linear and macrocyclic gadolinium-based contrast agents. Invest Radiol 2017;52:324-33 CrossRef Medline

22. McDonald RJ, McDonald JS, Dai D, et al. Comparison of gadolinium concentrations within multiple rat organs after intravenous administration of linear versus macrocyclic gadolinium chelates. $R a-$ diology 2017;285:536-45 CrossRef Medline

23. Bussi S, Coppo A, Botteron C, et al. Differences in gadolinium reten- tion after repeated injections of macrocyclic MR contrast agents to rats. J Magn Reson Imaging 2017 Jul 21. [Epub ahead of print] CrossRef Medline

24. Smith AP, Marino M, Roberts J, et al. Clearance of gadolinium from the brain with no pathologic effect after repeated administration of gadodiamide in healthy rats: an analytical and histologic study. $R a$ diology 2017;282:743-51 CrossRef Medline 